\title{
Ultrathin silicatene/silicon-carbide hybrid film on a metal substrate.
}

Bing Yang, Shamil Shaikhutdinov, * Hans-Joachim Freund

Abteilung Chemische Physik, Fritz-Haber Institut der Max-Planck Gesellschaft, Faradayweg 4-6, Berlin 14195, Germany

\begin{abstract}
Layered graphene/silica heterostructures may become interesting materials in nanotechnology with yet unknown properties. We have attempted here to intercalate graphene into a silicatene/Ru(0001) interface. The experimental results obtained by $\mathrm{x}$-ray photoelectron spectroscopy, low energy electron diffraction, infrared reflection-absorption spectroscopy, and scanning tunneling microscopy suggest the formation of a well-ordered hybrid structure consisting of a single-layer silicatene on top of a silicon carbide monolayer adsorbed on a metal substrate.
\end{abstract}

Keywords: Graphene; Silicatene; Intercalation; Interface.

*E-mail: shaikhutdinov@fhi-berlin.mpg.de 


\section{Introduction}

Thin silica films are one of the key materials in many modern technological applications. Recent progress in fabrication of well-defined, ultrathin silica films on metals opened up opportunities for fundamental studies of silica surfaces.[1] The structural motif of such films is a hexagonal layer of corner-sharing $\left[\mathrm{SiO}_{4}\right]$ tetrahedra (so called "silicatene"). A single-layer silicatene is bound to a metal support through Si-O-Metal linkages [2]. When supported on noble metal substrates such as Ru(0001) and Pt(111), a double-layer silicatene is formed which is weakly bound to the support via dispersive forces [3-5]. There are certain topological similarities between silicatene and graphene [6]. Apparently, a high flexibility of the Si-O bonds in silica provides an additional degree of freedom while adopting the most stable structure.

Combining these two (graphene and silicatene) materials in one system could, in principle, result in hybrid structures of yet unknown, but potentially interesting properties. Although there were few attempts to support graphene on a thermally grown $\mathrm{SiO}_{2} / \mathrm{Si}(111)$ substrate using lithography techniques [7], interaction of graphene with silicon (silica) has been addressed only recently. Wang et al. [8] observed that Si rapidly diffuses from the multilayer graphene surface to the graphene/SiC(000-1) interface upon heating. The reason the Si intercalated and did not form a new stable SiC layer remained unclear. On the basis of density functional theory (DFT) calculations, Kaloni et al. [9] suggested an intercalation mechanism where Si migrates through atomic defects of the graphene sheet. Using scanning tunneling microscopy (STM) and x-ray photoelectron spectroscopy (XPS), Mao et al. [10] showed that Si intercalating the graphene grown on $\mathrm{Ru}(0001)$ not only weakens the interaction of graphene with the metal substrate but also retains its superlative properties. With the aid of DFT calculations and STM, Cui et al. [11] proposed another intercalation mechanism, in which the penetration of $\mathrm{Si}$ through the graphene lattice is facilitated by a Si-C exchange process. Recently, Lizzit et al. [12] have reported insulation of epitaxial graphene on $\mathrm{Ru}(0001)$ by its sequential exposure to silicon and oxygen, which resulted in an amorphous thin silica film 
between the graphene and the metal as judged by XPS. However, the atomic structure of the silica formed underneath the graphene was not established. Finally, Huang et al. [13] reported accidental formation of a double-layer silicatene on graphene during chemical vapor deposition of graphene on copper foil. Corresponding DFT calculations suggested that graphene hardly forms covalent bonds with a silica layer, albeit exhibits some stabilizing effects.

The present work was carried out in attempts to fabricate well-defined graphene/silicatene layered structures on a metal substrate. Since silicatenes are commonly prepared on metal supports by oxidation of a Si overlayer at very high temperatures [1], graphene does not survive under these conditions and ultimately decompose via gasification into $\mathrm{CO}$ and $\mathrm{CO}_{2}$. To overcome this issue, it is near at hand to reverse the preparation process and start with silicatene as a substrate for the subsequent deposition of graphene. In particular, our recent studies showed that, similar to graphene/metal systems, the interface between a double-layer silicatene and a $\mathrm{Ru}(0001)$ surface can readily be intercalated by metallic atoms [14] as well as gas molecules such as $\mathrm{CO}$ and $\mathrm{D}_{2}[15]$. In this work, we report on the results only obtained for double-layer silicatene.

\section{Materials and methods}

The experiments were performed in an ultra-high vacuum (UHV) chamber equipped with a low energy electron diffraction (LEED), infrared reflection absorption spectroscopy (IRAS), XPS, and STM. The IRA-spectra (Bruker IFS 66v) were recorded using $\mathrm{p}$-polarized light at $84^{\circ}$ grazing angle of incidence (resolution $4 \mathrm{~cm}^{-1}$ ). XP-spectra were obtained with the commercial $\mathrm{X}$-ray $\left(\mathrm{Mg} \mathrm{K}_{\alpha}=1253.6 \mathrm{eV}\right)$ source and Scienta SES 200 analyzer at normal electron emission (typical resolution $200 \mathrm{meV}$ ). The binding energies $(\mathrm{BE})$ of core levels were referenced to the Fermi edge of a Ru substrate.

The bilayer silicatene films were grown on $\mathrm{Ru}(0001)$ as described in detail elsewhere [5]. Briefly, silicon is vapor deposited onto oxygen precovered 
$30(2 \times 2)-\mathrm{Ru}(0001)$ surface at $\sim 100 \mathrm{~K}$, followed by oxidation at $\sim 1200 \mathrm{~K}$ in $10^{-6} \mathrm{mbar}$ $\mathrm{O}_{2}$. Exposure to gases at pressures in the mbar range was performed in a separate cell, connected to the UHV chamber through a gate valve. After the treatment, the cell is pumped out down to $10^{-8} \mathrm{mbar}$ and the sample is transferred back to the UHV chamber. Ethylene $\left(\mathrm{C}_{2} \mathrm{H}_{4}, 99.5 \%\right.$, from Linde) was used as supplied.

\section{Results and discussion.}

Before we address the results, it is instructive here to recall the characteristic fingerprints of silicatene on metals, in particular on $\mathrm{Ru}(0001)$ used here. Single-layer silicatene exhibits the principal IRA-band at $1135 \mathrm{~cm}^{-1}$ associated with the stretching of a Si-O-Ru linkage $[3,5]$. The double-layer silicatene shows sharp phonon bands at $1300 \mathrm{~cm}^{-1}$ and (a weaker) at $696 \mathrm{~cm}^{-1}$, which are associated with the stretching of Si-O-Si linkages between two silicatene layers and the bending mode of surface Si-O-Si bonds, respectively [3]. All Si ions in silicatene are in the oxidation state $4+$ as evidenced by XPS. Compared to the O2p level for oxygen in siloxane ( $\mathrm{Si}-\mathrm{O}-\mathrm{Si}$ ) bonds, oxygen in Si-O-Ru linkages shows an $1.5 \mathrm{eV}$ lower binding energy. In addition, the films may contain O atoms directly adsorbed on the Ru(0001) surface [16]. Crystalline silicatene shows (2x2)-Ru(0001) diffraction spots in LEED, but forms a diffraction ring (Fig. 1a) for double-layer silicatene in amorphous (glassy) state, both structures often coexisting [17].
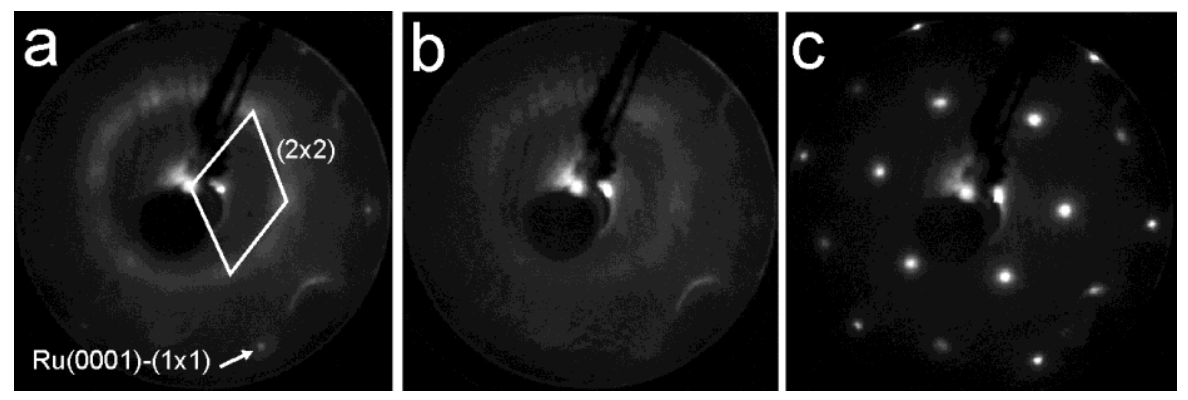

Figure 1. LEED patterns $(60 \mathrm{eV})$ of double-layer silicatene measured in UHV at $300 \mathrm{~K}$ : (a) as prepared; (b) after exposure to 10 mbar of ethylene at $450 \mathrm{~K}$; (c) subsequent annealing in UHV at $1100 \mathrm{~K}$. 
For the preparation of graphene layers on metals, decomposition of ethylene or other unsaturated hydrocarbons is commonly used. Exposure of silicatene to ethylene under typical pressures $\left(\sim 10^{-6} \mathrm{mbar}\right)$ used in UHV chambers caused no considerable changes in IRAS, XPS and LEED, since the siloxane-terminated surface is essentially inert. On the other hand, the exposure at elevated temperatures ( 1100 $\mathrm{K}$ ) resulted in full reduction of the silica layer as no more oxygen was detected in XP-spectra.

Exposure to $10 \mathrm{mbar}_{2} \mathrm{H}_{4}$ for $20 \mathrm{~min}$ at $450 \mathrm{~K}$ attenuates the LEED pattern considerably (Fig. 1b). The phonon region of the corresponding IRA-spectrum (Fig. 2, red line) shows tiny changes compared to the "as prepared" sample, thus suggesting that the principal structure of silicatene is not affected by this treatment. However, some additional bands are observed in the region between 3000 and $2800 \mathrm{~cm}^{-1}$ (as shown in Figure S1(a) in the Supplementary Information) which are characteristic for $v(\mathrm{C}-\mathrm{H})$ stretching modes of adsorbed $\mathrm{CH}_{\mathrm{x}}$ species. The presence of carbonaceous species on Ru by XPS is difficult to justify due to overlapping of the Ru3d $d_{3 / 2}$ and C1s signals (see Figure S1(b) in the SI). In agreement with IRAS, XPS results show that the silica stoichiometry is maintained; however, the Si2p and 01s levels are equally, by $1.9 \mathrm{eV}$, shifted towards higher BEs as shown in Fig. 3.

Core level shifts are commonly observed for thin oxide films grown on metal substrates (see, for example, ref. [18]). Those are usually explained within the well-known Schottky model of a metal/semiconductor interface, where alignment of the Fermi levels in two materials results in a corresponding Schottky barrier and causes band bending in the oxide film. Although band bending can be neglected for ultrathin oxide films, the absolute BE values measured by XPS will depend on the work function of a metal support and the position of a so-called "zero charge point" level [19] used for large-gap semiconductors and insulators, such as silica and alumina. In the absence of considerable structural changes for a weakly bound silica film during gas adsorption, as judged here by IRAS, the BE shifts reflect changes in the work function of a metal support. Such a behavior has previously been observed 
for the $\mathrm{O}$ atoms directly bonded to the $\mathrm{Ru}(0001)$ surface underneath the film [16]. Figure 3 shows that the signal at $530 \mathrm{eV}$, associated with the $\mathrm{O}$ ad-atoms on $\mathrm{Ru}$ in the "as prepared" sample, disappears upon ethylene exposure. Solely oxygen desorption would cause the BE shift by about $0.8 \mathrm{eV}$ [16] at most, i.e. much smaller than $1.9 \mathrm{eV}$ observed. On the other hand, the shift is very close to the difference in the work functions of the $30(2 \times 2)-R u(0001)$ and $\mathrm{C} / \mathrm{Ru}(0001)$ surfaces (i.e. 6.4 and $4.5 \mathrm{eV}$, respectively) $[20,21]$. Therefore, one may conclude that the $R u(0001)$ surface is covered by carbon (and/or carbonaceous) species upon ethylene exposure at elevated pressures. Certainly, ethylene can only dissociate on the Ru(0001) surface. Ethylene either adsorbs in macroscopic "holes" in the film, thus exposing a Ru(0001) support, or penetrates through the large "pores" in the amorphous silicatene as previously demonstrated for $\mathrm{CO}[15]$.

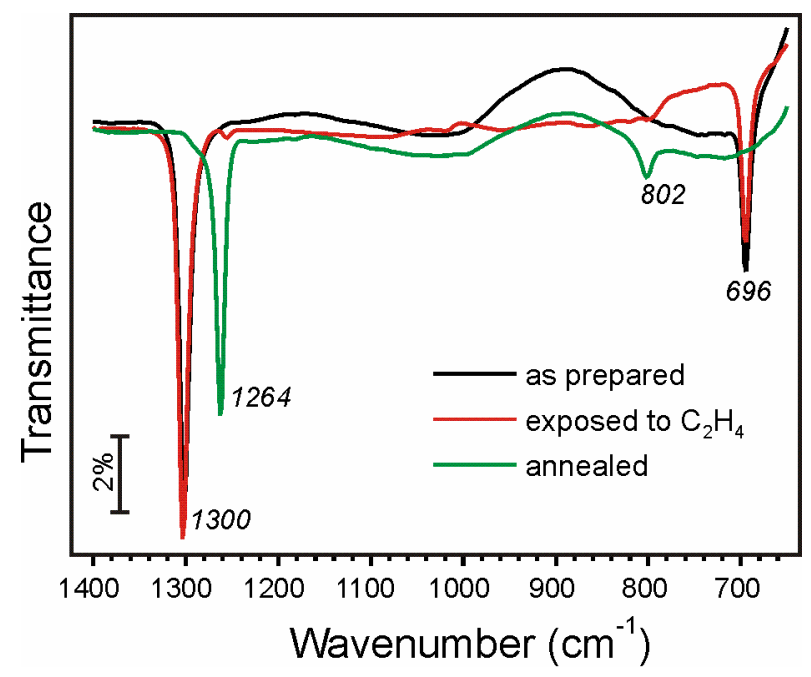

Figure 2. IRA-spectra of double-layer silicatene: as prepared (black), after exposure to 10 mbar of ethylene at $450 \mathrm{~K}$ (red), and subsequent annealing in UHV at $1100 \mathrm{~K}$ (green). 


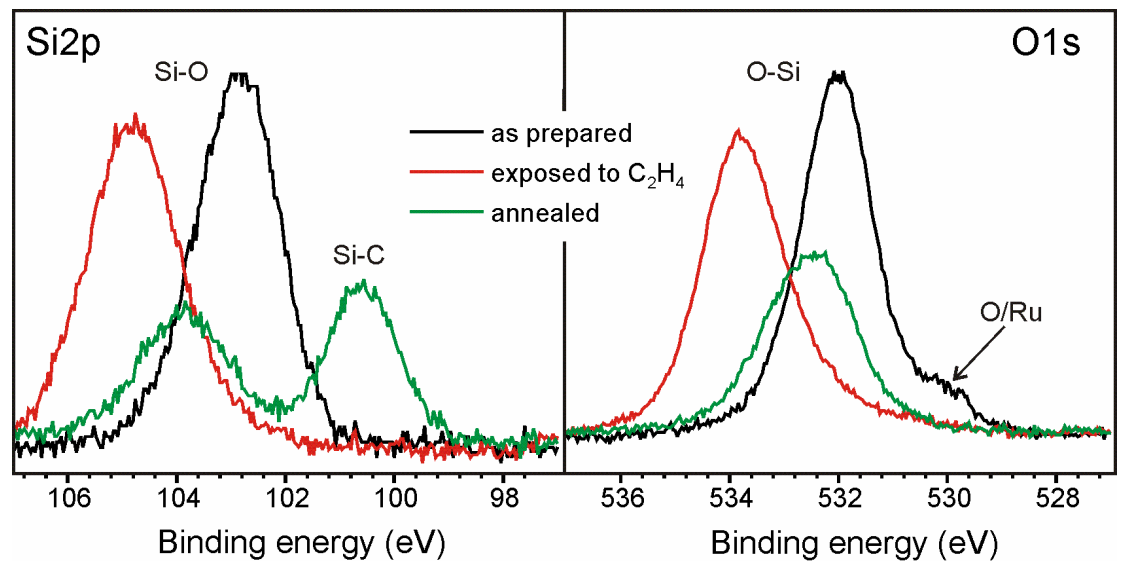

Figure 3. XP-spectra of the Si2p and O1s levels in double-layer silicatene: as prepared (black), after exposure to 10 mbar of ethylene at $450 \mathrm{~K}$ (red), and subsequent annealing in UHV at $1100 \mathrm{~K}$ (green).

In the next step, the sample was annealed in UHV to the temperatures commonly used for graphene formation on $\mathrm{Ru}(0001)$ [22]. Annealing at $1100 \mathrm{~K}$ for 3 min resulted in substantial structural changes. Notably, the annealed film became well-ordered, showing sharp (2x2) diffraction spots (Fig. 1C). In good agreement with LEED, STM images (Fig. 4) revealed domains with a honeycomb-like structure with a 5.5 A periodicity, which are separated by defect lines mostly consisting of large depressions assigned to the large $\mathrm{N}$-membered rings $[6,23]$. No Moire-like superstructures are observed in LEED and STM, otherwise expected for the formation of graphene adsorbed on $\operatorname{Ru}(0001)[10,11]$. 

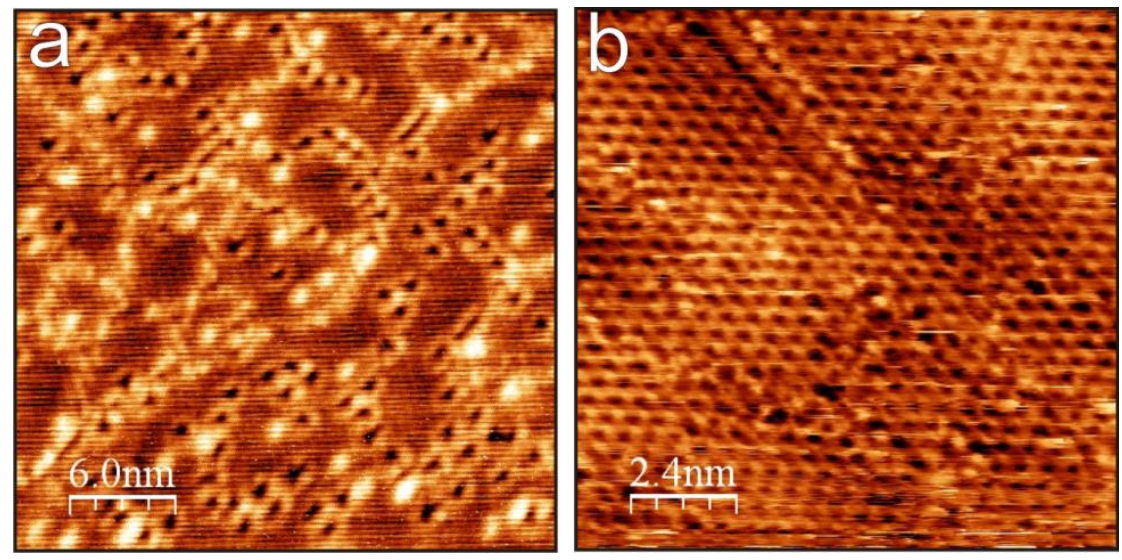

Figure 4. High-resolution STM images of the silicatene film exposed to $10 \mathrm{mbar}$ of ethylene at $450 \mathrm{~K}$ and then annealed in UHV to $1100 \mathrm{~K}$. Sample bias: $-3 \mathrm{~V}(\mathrm{a}),-1 \mathrm{~V}(\mathrm{~b})$, tunneling current $0.1 \mathrm{nA}$.

The corresponding IRA-spectrum, shown in Fig. 2, revealed a strong band at $1264 \mathrm{~cm}^{-1}$ and a weaker band at $802 \mathrm{~cm}^{-1}$, while the original bands at 1302 and 696 $\mathrm{cm}^{-1}$ disappeared. XPS inspection of the same sample (Fig. 3) shows that the amount of oxygen is decreased by a factor of $\sim 2$, whereas the total amount of $\mathrm{Si}$ in the system remains the same, although it splits in two, almost equally populated species. The high BE signal (at $\sim 104 \mathrm{eV}$ ) remains assigned to $\mathrm{Si}$ in the 4+ state, and its shift may, again, be associated with the work function change. Regarding the low BE signal at 101 eV, XPS studies available in the literature on Si-based materials allow us to assign this peak to $\mathrm{Si}$ cations coordinated to $\mathrm{C}$ like in silicon carbide [24-26]. Therefore, the XPS results suggest that about a half of oxygen ions in the silicatene are replaced by carbon upon UHV annealing. The extent of such substitution depends on the ethylene exposure time. In the samples studied, both original and new IR bands showed an inverse relation without substantial shift (see Fig. S2 in the $\mathrm{SI})$. The intensity of new bands is proportional to the amount of $\mathrm{Si}$ in the low BE state, i.e. in Si-C environment. These results are indicative for the phase coexistence of the carbon-containing and the pristine silicatene layers, the former expands in area until it covers the whole surface. 
In double-layer silicatene, there are three non-equivalent oxygen species (see Fig. 5a): $\mathrm{O}_{t}$ and $\mathrm{O}_{\mathrm{b}}$ are oxygens in the top and bottom layers coordinated either to $\mathrm{Si}_{t}$ or $\mathrm{Si}_{b}$ cations, respectively; $\mathrm{O}_{m}$ is oxygen linking two single-layer silicatenes thus forming a $\mathrm{Si}_{\mathrm{t}}-\mathrm{O}_{\mathrm{m}}-\mathrm{Si}_{\mathrm{b}}$ linkage. Those oxygen $\left(\mathrm{O}_{t}, \mathrm{O}_{\mathrm{m}}\right.$, and $\left.\mathrm{O}_{\mathrm{b}}\right)$ species are populated in the ratio 3:2:3 per unit cell. Substitution of $\mathrm{O}_{\mathrm{m}}$ atoms by carbon would result in equivalent $\mathrm{Si}$ species and oxygen depletion by $25 \%$, thus contradicting the XPS results showing two Si species and oxygen depletion by about $50 \%$. Random distribution of carbon atoms replacing oxygen in top and bottom layers would, again, result in equivalent $\mathrm{Si}$ species. Therefore, one has to replace either $\mathrm{O}_{t}$ or $\mathrm{O}_{b}$ species. In this case, oxygen depletion would account $37.5 \%$, i.e. reasonably close to $~ 50 \%$ as observed. Since carbon atoms were adsorbed on the Ru support prior to the UHV annealing, it seems plausible that intercalated carbon reacts with oxygen in the bottom layer, ultimately substituting $\mathrm{O}_{\mathrm{b}}$ species. The released oxygen atoms adsorb on the Ru surface and then either recombinatively desorb upon annealing, or react with unreacted carbon atoms to form $\mathrm{CO}$ which also desorbs. A higher than expected oxygen depletion ( 50\% vs $37.5 \%$ ) in the films could be explained by partial reduction of the silica film by carbon, thus resulting in areas of oxygen-deficient silicon carbide structures.

In principle, the multi-valency of carbon allows all or some $\mathrm{C}$ atoms in the bottom layer to form bonds with the Ru surface. This would have a stabilization effect and result in better film ordering as observed by LEED (Fig. 1). Indeed, good crystallinity of single layer silicatenes grown on Mo(112) [2] and $\mathrm{Ru}(0001)$ [5] is primarily driven by strong Si-O-Metal bonds leading to an epitaxial registry with a metal surface. Also our recent study of Fe-doped silicate films [27] showed promotional effect of Fe ions in the bottom layer on film ordering.

This analysis allows us to propose the structure, depicted in Fig. 5b, which fits well the experimental results obtained so far. In fact, the proposed structure is nothing else but a single layer silicatene placed on top of a SiC-like monolayer formed on Ru(0001). Beside the above-discussed arguments based on LEED and XPS data, the proposed structure agrees well with the IRAS results showing that the Si-O-Si linkage is essentially maintained, as the corresponding stretching frequency at 1300 
$\mathrm{cm}^{-1}$ is only by $35 \mathrm{~cm}^{-1}$ red-shifted. It is noteworthy that another band (at $802 \mathrm{~cm}^{-1}$ ) is close to the one at $790 \mathrm{~cm}^{-1}$, observed for a single-layer silicatene on $\mathrm{Ru}(0001)$ and associated with asymmetric stretching of $\mathrm{Si}-\mathrm{O}-\mathrm{Ru}$ linkage combined with $\mathrm{O}-\mathrm{Si}-\mathrm{O}$ bending mode. The latter finding is also consistent with the proposed model, suggesting a stronger bonding of the bottom layer to the metal support as compared to pristine double-layer silicatene.
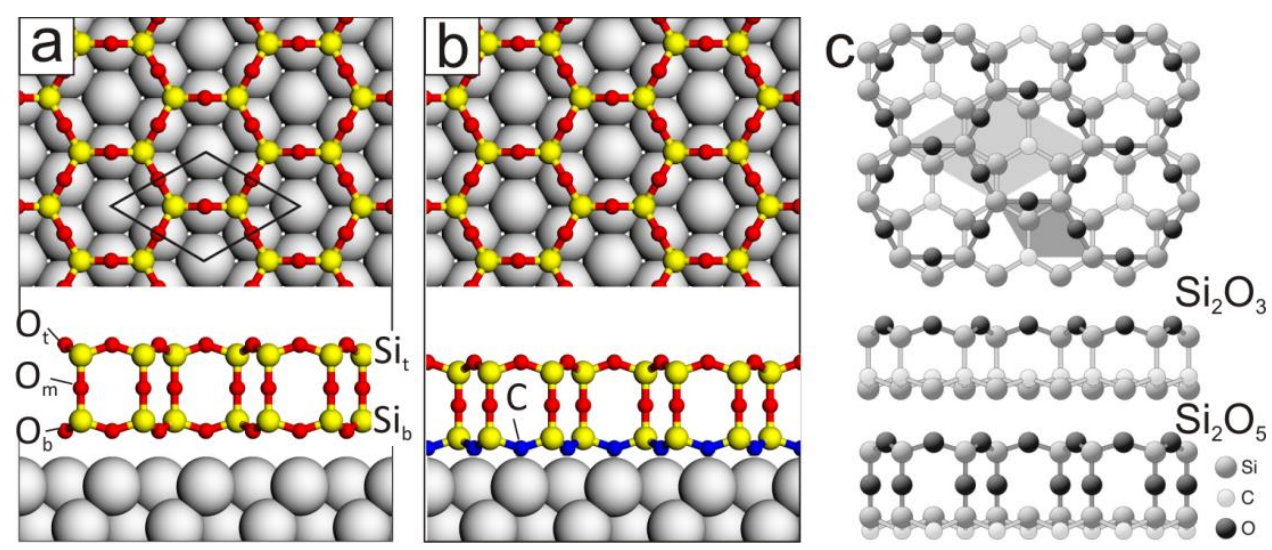

Figure 5. a) Top and cross views of double-layer silicatene on $\mathrm{Ru}(0001)$. The unit cell is indicated. b) Tentative structure of the film prepared in this study (see text for details). c) Top and side views of the $\mathrm{Si}_{2} \mathrm{O}_{3}$ and $\mathrm{Si}_{2} \mathrm{O}_{5}$ silicate structures on $\mathrm{SiC}(0001)$ as proposed in ref. [28]. Dark and light shaded areas indicate the unit cell of SiC and silica overlayer, respectively.

The model, depicted in Fig. 5b, is very similar to those proposed by Heinz and coworkers [28] for ultrathin silica films grown on $\mathrm{SiC}(0001)$, shown in Fig. 5c for comparison. Depending on surface termination of $\mathrm{SiC}$, i.e. either $\mathrm{C}$ or $\mathrm{Si}$, two structures were suggested on the basis of I/V LEED measurements. Further DFT study [29] showed that in the case of $\mathrm{C}$-terminated surface, both the $\mathrm{Si}_{2} \mathrm{O}_{3}$ and the $\mathrm{Si}_{2} \mathrm{O}_{5}$ models have roughly the same formation energy, whereas the $\mathrm{Si}_{2} \mathrm{O}_{5}$ model is energetically much more favorable on the Si-terminated surface. The DFT-calculated structural parameters were in excellent agreement with the LEED results.

\section{Conclusions}


In attempts to intercalate graphene into a silicatene/Ru(0001) interface, we have fabricated a well-ordered hybrid structure consisting of a single-layer silicatene on top of a silicon carbide monolayer adsorbed on a metal substrate. The structure reported here may be interesting for metal/oxide/semiconductor (MOS) systems. The formation of a high quality oxide layer on $\mathrm{SiC}$ is a key requirement for MOS devices based on this material $[30,31]$. In addition, thin films of silicon oxycarbides, i.e. having $\mathrm{Si}$ coordinated both to $\mathrm{C}$ and $\mathrm{O}$, were shown to exhibit many interesting, particularly optical, properties [32, 33]. We believe that the observed hybrid structure may provide a basis for development of new generation two-dimensional systems with unique properties

In addition, the results show that fabrication of sandwiched graphene/silicatene structures on a metal substrate seems to be hardly possible by synthesis based on an intercalation approach. Perhaps, sedimentation of graphene and silicatene "flakes" could be more feasible for those objectives. However, in contrast to graphene, reliable preparation of free-standing silicatene remains unknown.

\section{Acknowledgements.}

The authors gratefully acknowledge financial support by Deutsche Forschungsgemeinschaft (DFG) through Collaborative Research Center 1109 and the Fonds der Chemischen Industrie.

\section{References:}

[1] S. Shaikhutdinov, H.-J. Freund, Ultrathin Silica Films on Metals: The Long and Winding Road to Understanding the Atomic Structure, Advanced Materials, 25 (2013) 49-67.

[2] J. Weissenrieder, S. Kaya, J.-L. Lu, H.-J. Gao, S. Shaikhutdinov, H.-J. Freund, M. Sierka, T.K. Todorova, J. Sauer, Atomic Structure of a Thin Silica Film on a Mo(112) Substrate: A Two-Dimensional Network of $\mathrm{SiO}_{4}$ Tetrahedra, Physical Review Letters, 95 (2005) 076103.

[3] D. Löffler, J.J. Uhlrich, M. Baron, B. Yang, X. Yu, L. Lichtenstein, L. Heinke, C. Büchner, M. Heyde, S. Shaikhutdinov, H.J. Freund, R. Włodarczyk, M. Sierka, J. Sauer, Growth and Structure of Crystalline Silica Sheet on Ru(0001), Physical Review Letters, 105 (2010) 146104.

[4] X. Yu, B. Yang, J.A. Boscoboinik, S. Shaikhutdinov, H.-J. Freund, Support effects on the atomic structure of ultrathin silica films on metals, Applied Physics Letters, 100 (2012) 151608-151604.

[5] B. Yang, W.E. Kaden, X. Yu, J.A. Boscoboinik, Y. Martynova, L. Lichtenstein, M. Heyde, M. Sterrer, R. 
Wlodarczyk, M. Sierka, J. Sauer, S. Shaikhutdinov, H.-J. Freund, Thin silica films on Ru(0001): monolayer, bilayer and three-dimensional networks of $\left[\mathrm{SiO}_{4}\right]$ tetrahedra, Physical Chemistry Chemical Physics, 14 (2012) 11344.

[6] B. Yang, J.A. Boscoboinik, X. Yu, S. Shaikhutdinov, H.-J. Freund, Patterned Defect Structures Predicted for Graphene Are Observed on Single-Layer Silica Films, Nano Letters, 13 (2013) 4422-4427. [7] M. Ishigami, J.H. Chen, W.G. Cullen, M.S. Fuhrer, E.D. Williams, Atomic Structure of Graphene on SiO2, Nano Letters, 7 (2007) 1643-1648.

[8] F. Wang, K. Shepperd, J. Hicks, M.S. Nevius, H. Tinkey, A. Tejeda, A. Taleb-Ibrahimi, F. Bertran, P. Le Fèvre, D.B. Torrance, P.N. First, W.A. de Heer, A.A. Zakharov, E.H. Conrad, Silicon intercalation into the graphene-SiC interface, Physical Review B, 85 (2012) 165449.

[9] T.P. Kaloni, M.U. Kahaly, Y.C. Cheng, U. Schwingenschlogl, Mechanism of Si intercalation in defective graphene on SiC, Journal of Materials Chemistry, 22 (2012) 23340-23343.

[10] J. Mao, L. Huang, Y. Pan, M. Gao, J. He, H. Zhou, H. Guo, Y. Tian, Q. Zou, L. Zhang, H. Zhang, Y. Wang, S. Du, X. Zhou, A.H. Castro Neto, H.-J. Gao, Silicon layer intercalation of centimeter-scale, epitaxially grown monolayer graphene on Ru(0001), Applied Physics Letters, 100 (2012) -.

[11] Y. Cui, J. Gao, L. Jin, J. Zhao, D. Tan, Q. Fu, X. Bao, An exchange intercalation mechanism for the formation of a two-dimensional Si structure underneath graphene, Nano Res., 5 (2012) 352-360.

[12] S. Lizzit, R. Larciprete, P. Lacovig, M. Dalmiglio, F. Orlando, A. Baraldi, L. Gammelgaard, L. Barreto, M. Bianchi, E. Perkins, P. Hofmann, Transfer-Free Electrical Insulation of Epitaxial Graphene from its Metal Substrate, Nano Letters, 12 (2012) 4503-4507.

[13] P.Y. Huang, S. Kurasch, A. Srivastava, V. Skakalova, J. Kotakoski, A.V. Krasheninnikov, R. Hovden, Q. Mao, J.C. Meyer, J. Smet, D.A. Muller, U. Kaiser, Direct Imaging of a Two-Dimensional Silica Glass on Graphene, Nano Letters, 12 (2012) 1081-1086.

[14] W.E. Kaden, C. Büchner, L. Lichtenstein, S. Stuckenholz, F. Ringleb, M. Heyde, M. Sterrer, H.-J. Freund, L. Giordano, G. Pacchioni, C.J. Nelin, P.S. Bagus, Understanding surface core-level shifts using the Auger parameter: A study of Pd atoms adsorbed on ultrathin $\mathrm{SiO}_{2}$ films, Physical Review $\mathrm{B}, 89$ (2014) 115436.

[15] E. Emmez, B. Yang, S. Shaikhutdinov, H.J. Freund, On the permeation of a single layer $\mathrm{SiO}_{2}$ membrane and chemistry in confined space, Journal of Physical Chemistry C, doi: 10.1021/jp503253a [16] R. Włodarczyk, M. Sierka, J. Sauer, D. Löffler, J.J. Uhlrich, X. Yu, B. Yang, I.M.N. Groot, S. Shaikhutdinov, H.J. Freund, Tuning the electronic structure of ultrathin crystalline silica films on Ru(0001), Physical Review B, 85 (2012) 085403.

[17] M. Heyde, S. Shaikhutdinov, H.J. Freund, Two-dimensional silica: Crystalline and vitreous, Chemical Physics Letters, 550 (2012) 1-7.

[18] Y. Wu, E. Garfunkel, T.E. Madey, Growth and oxidation of ultra-thin Al films on the Re (0001) surface, Surface Science, 365 (1996) 337-352.

[19] C. Noguera, Physics and Chemistry at Oxide Surfaces, Cambridge University Press, 1996.

[20] F.J. Himpsel, K. Christmann, P. Heimann, D.E. Eastman, P.J. Feibelman, ADSORBATE BAND DISPERSIONS FOR C ON RU(0001), Surface Science, 115 (1982) L159-L164.

[21] Y.D. Kim, A.P. Seitsonen, S. Wendt, J. Wang, C. Fan, K. Jacobi, H. Over, G. Ertl, Characterization of various oxygen species on an oxide surface: RuO2(110), J. Phys. Chem. B, 105 (2001) 3752-3758.

[22] H. Zhang, Q. Fu, Y. Cui, D. Tan, X. Bao, Growth Mechanism of Graphene on Ru(0001) and 02 Adsorption on the Graphene/Ru(0001) Surface, The Journal of Physical Chemistry C, 113 (2009) 8296-8301. 
[23] L. Lichtenstein, C. Büchner, B. Yang, S. Shaikhutdinov, M. Heyde, M. Sierka, R. Włodarczyk, J. Sauer, H.-J. Freund, The Atomic Structure of a Metal-Supported Vitreous Thin Silica Film, Angewandte Chemie International Edition, 51 (2012) 404-407.

[24] I. Kusunoki, Y. Igari, XPS study of a $\mathrm{SiC}$ film produced on $\mathrm{Si}(100)$ by reaction with a $\mathrm{C}_{2} \mathrm{H}_{2}$ beam, Applied Surface Science, 59 (1992) 95-104.

[25] A. Santoni, R. Frycek, P. Castrucci, M. Scarselli, M. De Crescenzi, XPS and STM study of SiC synthesized by acetylene and disilane reaction with the Si(100)-(2x1) surface, Surface Science, 582 (2005) 125-136.

[26] M. Schürmann, S. Dreiner, U. Berges, C. Westphal, Structure of the interface between ultrathin $\mathrm{SiO}_{2}$ films and 4H-SiC(0001), Physical Review B, 74 (2006) 035309.

[27] R. Włodarczyk, J. Sauer, X. Yu, J.A. Boscoboinik, B. Yang, S. Shaikhutdinov, H.-J. Freund, Atomic Structure of an Ultrathin Fe-Silicate Film Grown on a Metal: A Monolayer of Clay?, Journal of the American Chemical Society, 135 (2013) 19222-19228.

[28] J. Bernhardt, J. Schardt, U. Starke, K. Heinz, Epitaxially ideal oxide-semiconductor interfaces: Silicate adlayers on hexagonal (0001) and (0001) SiC surfaces, Applied Physics Letters, 74 (1999) 1084-1086.

[29] W. Lu, P. Krüger, J. Pollmann, Atomic and electronic structure of silicate adlayers on polar hexagonal SiC surfaces, Physical Review B, 61 (2000) 13737-13744.

[30] C. Raynaud, Silica films on silicon carbide: a review of electrical properties and device applications, Journal of Non-Crystalline Solids, 280 (2001) 1-31.

[31] V. Presser, K.G. Nickel, Silica on Silicon Carbide, Critical Reviews in Solid State and Materials Sciences, 33 (2008) 1-99.

[32] S. Gallis, V. Nikas, H. Suhag, M. Huang, A.E. Kaloyeros, White light emission from amorphous silicon oxycarbide $\left(\mathrm{a}-\mathrm{SiC}_{\mathrm{x}} \mathrm{O}_{\mathrm{y}}\right)$ thin films: Role of composition and postdeposition annealing, Applied Physics Letters, 97 (2010) 081905-4.

[33] C. Pantano, A. Singh, H. Zhang, Silicon Oxycarbide Glasses, Journal of Sol-Gel Science and Technology, 14 (1999) 7-25. 